\title{
Common 4977 bp deletion and novel alterations in mitochondrial DNA in Vietnamese patients with breast cancer
}

\author{
Jan Dimberg ${ }^{1 \dagger}$, Thai Trinh Hong ${ }^{2 \dagger}$, Linh Tu Thi Nguyen ${ }^{2}$, Marita Skarstedt ${ }^{3}$, Sture Löfgren ${ }^{3}$ and Andreas Matussek ${ }^{4^{*}}$
}

\begin{abstract}
Mitochondrial DNA (mtDNA) has been proposed to be involved in carcinogenesis and ageing. The mtDNA $4977 \mathrm{bp}$ deletion is one of the most frequently observed mtDNA mutations in human tissues and may play a role in breast cancer (BC). The aim of this study was to investigate the frequency of mtDNA 4977 bp deletion in BC tissue and its association with clinical factors.

We determined the presence of the 4977 bp common deletion in cancer and normal paired tissue samples from 106 Vietnamese patients with BC by sequencing PCR products.

The mtDNA 4977 bp deletion was significantly more frequent in normal tissue in comparison with paired cancer tissue. Moreover, the incidence of the 4977 bp deletion in BC tissue was significantly higher in patients with estrogen receptor (ER) positive as compared with ER negative BC tissue. Preliminary results showed, in cancerous tissue, a significantly higher incidence of novel deletions in the group of patients with lymph node metastasis in comparison with the patients with no lymph node metastasis.

We have found $4977 \mathrm{bp}$ deletion in mtDNA to be a common event in BC and with special reference to ER positive BC. In addition, the novel deletions were shown to be related to lymph node metastasis. Our finding may provide complementary information in prediction of clinical outcome including metastasis, recurrence and survival of patients with $\mathrm{BC}$.
\end{abstract}

Keywords: Breast cancer; Mitochondrial DNA mutation; mtDNA deletion

\section{Introduction}

The incidence of different cancers have increased both in developed and in developing countries (Jemal et al. 2011). Breast cancer (BC) is one of the most common cancers affecting women worldwide and the incidence is rapidly rising in Asian countries. In Vietnam, the incidence rate is 12 to 27per 100000 (Anh \& Duc 2002; Le et al. 2002) while the incidence for women living in Western countries is about 80 to 100 per 100000 (Jemal et al. 2011).

The development of $\mathrm{BC}$ involves a progression through intermediate states and processes leading to evolution to carcinoma in situ, invasive carcinoma and metastasis.

\footnotetext{
*Correspondence: andreas.matussek@rjl.se

${ }^{\dagger}$ Equal contributors

${ }^{4}$ Departments of Laboratory Services, Ryhov County Hospital, SE-551 85 Jönköping, Sweden

Full list of author information is available at the end of the article
}

Mutations in nuclear genes such as tumor-suppressor genes and oncogenes, but also environmental exposures contribute to the development of $\mathrm{BC}$ (McPherson et al. 2000; Polyak 2007; Schwartz et al. 2008). For example high penetrance genes as BRCA1, BRCA2, PTEN and TP53 are responsible for the hereditary $\mathrm{BC}$ syndromes (Polyak 2007; Schwartz et al. 2008).

It is necessary to identify molecular markers to predict the progression, metastasis, recurrence and survival in BC. Hormone receptors status is used for identifying a high-risk phenotype and to select suitable regime for treatment (Banin Hirata et al. 2014). Other tumor markers suggested useful in diagnostic procedures and for prognosis in $\mathrm{BC}$ are expression of chemokines, chemokine receptors and growth factors (Banin Hirata et al. 2014).

Alongside the nuclear genome, the human cell contains hundreds to several thousand copies of the 16569 
base pair circular mitochondrial DNA (mtDNA) including 37 genes (Birch-Machin 2006; Penta et al. 2001). Within cells the mtDNA has the capacity to form a mixture of both wild-type and mutant mtDNA genotypes in a state called heteroplasmy (Birch-Machin 2006; Penta et al. 2001).

mtDNA has been proposed to be involved in carcinogenesis and ageing (Birch-Machin 2006; Penta et al. 2001) and somatic mtDNA mutations have been reported in various types of cancer, including BC (Penta et al. 2001; Chen et al. 2011; Eshaghian et al. 2006; Larman et al. 2012; Yadav \& Chandra 2013; Ye et al. 2008). The main reason for its involvement in carcinogenesis is probably that mtDNA has a high susceptibility to undergo mutations due to its lack of histones, limited repair mechanisms and a high rate of generation of reactive oxygen species (Birch-Machin 2006; Penta et al. 2001). The mitochondrial 4977 bp deletion, also known as the common deletion, is one of the most frequently observed mtDNA mutations and has been associated with different cancers (Chen et al. 2011; Eshaghian et al. 2006; Ye et al. 2008; Abnet et al. 2004; Dani et al. 2003). The deletion occurs between nucleotides 8470 and 13 447 and spans five tRNA genes and seven genes encoding subunits of cytochrome $c$ oxidase, ATPases and complex I (Chen et al. 2011; Ye et al. 2008). Moreover, the deletion has a $13 \mathrm{bp}$ direct repeat flanking the $5^{\prime}$ - and 3 '-end breakpoints at nucleotide position (np) 8470/8482 and np 13 447/13 459, respectively (Chen et al. 2011; Ye et al. 2008).

In this study, we determined the frequency of the 4977 bp deletion in $\mathrm{BC}$ and corresponding non-cancerous breast tissue samples from 106 Vietnamese patients with $\mathrm{BC}$.

\section{Materials and methods}

\section{Patients and tissue specimens}

This study comprised of 106 consecutive female patients with $\mathrm{BC}$, from northern Vietnam. Tissue specimens were collected when the patients underwent surgical resections at the National Cancer Hospital, Tam Hiep, Hanoi,
Vietnam. The mean age of the patients were 52 years (range 24-89 years). Clinicopathological characteristics from the patients were received from surgical and pathological records. Tumor tissue and adjacent normal tissue (about $5 \mathrm{~cm}$ from the tumor) from each patient were excised and immediately frozen at $80^{\circ} \mathrm{C}$ until further analysis.

Clinical and clinicopathologic classification and staging were determined according to the American Joint Committee on Cancer (AJCC) criteria. The tumors (invasive ductal carcinoma) were classified according to TNM staging system and the distribution was: T1N0M0 $(\mathrm{n}=8)$, T2N0M0 $(\mathrm{n}=42)$, T3N0M0 $(\mathrm{n}=5)$, T1N1M0 $(\mathrm{n}=2)$, T1N2M0 $(\mathrm{n}=2)$, T2N1M0 $(\mathrm{n}=28)$, T2N2M0 $(\mathrm{n}=3)$, T3N1M0 $(\mathrm{n}=7)$, T3N2M0 $(\mathrm{n}=1)$, T4N1M0 (6) and T2N1M1 $(\mathrm{n}=2)$.

Tumor grade of 79 patients was known: well differentiated $(\mathrm{n}=6)$, moderately differentiated $(\mathrm{n}=56)$ and poorly differentiated $(n=17)$. In 24 cases information regarding positive and negative expression of estrogen receptor (ER), progesterone receptor (PR) and human epidermal growth factor receptor 2 (HER2) in tumor tissue, was available. ER $+(n=12), P R+(n=5)$ and HER $2+(n=19)$. The study was approved by the local Ethics Committee at the Vietnam National University, Hanoi, Vietnam (2422/QD-KHCN) and all patients gave their consent to participate in the study.

\section{PCR assay}

DNA was isolated from all BCs and paired normal tissues by QIAamp DNA Mini kit (Qiagen, Hilden, Germany). To screen for the mitochondrial 4977 deletion, a nested PCR was developed to detect low levels of the deletion. Two pairs of PCR primers were designed for the first amplicon of $496 \mathrm{bp}$ and the second amplicon of $381 \mathrm{bp}$ (Table 1). For the first amplicon, the primers were designed to be distant enough to detect only mtDNAs containing deletions. To assess the presence of mtDNA and to detect heteroplasmy/homoplasmy regarding 4977 deletion, PCR primers were designed in the region of the genes NADH dehydrogenase 1 (ND1) and ND3

Table 1 Primer sequences and product sizes for mtDNA 4977 bp deletion analysis in this study

\begin{tabular}{|c|c|c|c|c|}
\hline Primer & Primer sequence & Position & Product & Note \\
\hline mtDNA-forward & 5'-GACGCCATAAAACTCTTCAC-3' & $3457-3476$ & $433 \mathrm{bp}$ & ND1-region \\
\hline mtDNA-reverse & 5'-GGTTGGTCTCTGCTAGTGTG-3' & $3889-3870$ & & \\
\hline 4977-1forward & 5'-TCAATGCTCGAAATCTGTGG-3' & $8167-8187$ & $496 \mathrm{bp}$ & First PCR \\
\hline 4977-1 reverse & 5'-GTTGACCTGTTAGGGTGAGAAG-3' & 13639-13618 & & \\
\hline 4977-2forward & 5'-ACAGTTTCATGCCCATCGTC-3' & $8196-8215$ & $381 \mathrm{bp}$ & Second PCR \\
\hline 4977-2reverse & 5'-GCGTTTGTGTATGATATGTTTGC-3' & 13553-13531 & & \\
\hline 10398-forward & 5'-CCTGCCACTAATAGTTATGTC-3' & 10307-10327 & $246 \mathrm{bp}$ & ND3-region \\
\hline 10398-reverse & 5'-GATATGAGGTGTGAGCGATA-3' & 10552-10533 & & \\
\hline
\end{tabular}




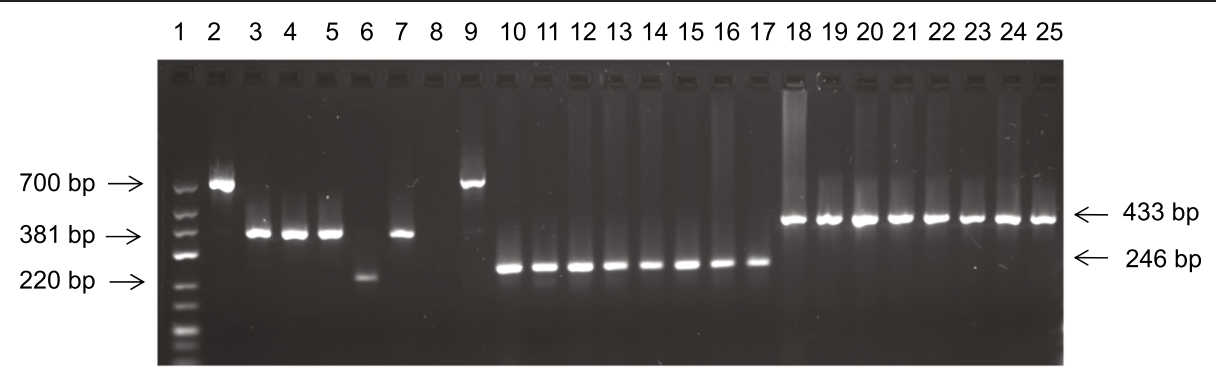

Figure 1 Agarose gel showing polymerase chain reaction (PCR) products from four breast cancer tissue/normal paired tissue. Nested PCR (381 bp, lane 2/3, 4/5, 6/7, 8/9); 10398 (246 bp, lane 10/11, 12/13, 14/15, 16/17); mtDNA (433 bp, lane 18/19, 20/21, 22/23, 24/25) and discovered novel deletions (700 bp, lane 2 and 9; 220 bp, lane 6). Lane 1, molecular marker.

resulting in products of $433 \mathrm{bp}$ and $246 \mathrm{bp}$, respectively (Table 1).

Except for the second PCR run for 4977 deletion, DNA was amplified in a total volume of $12.5 \mu$ l containing $0.2 \mu \mathrm{M}$ of each primer (TIB Molbiol, Berlin, Germany), $1.8 \mathrm{mM} \mathrm{MgCl} 2,200 \mu \mathrm{M}$ of each deoxynucleotide triphosphate, 0.04 units Taq DNA polymerase and reaction buffer $[20 \mathrm{mM}$ Tris- $\mathrm{HCl}(\mathrm{pH} 8.3)$, $20 \mathrm{mM} \mathrm{KCl}, 5 \mathrm{mM}\left(\mathrm{NH}_{4}\right)_{2} \mathrm{SO}_{4}$ ] (Fermentas, Burlington, Canada). Amplification was done with an initial denaturation at $95^{\circ} \mathrm{C}$ for $4 \mathrm{~min}$ followed by 35 cycles at $92^{\circ} \mathrm{C}$ for $30 \mathrm{~s}$ (denaturation), $54^{\circ} \mathrm{C}$ for $30 \mathrm{~s}$ (annealing), $72^{\circ} \mathrm{C}$ for $45 \mathrm{~s}$ (extension) and final elongation at $72^{\circ} \mathrm{C}$ for $10 \mathrm{~min}$. For the second PCR run regarding the 4977 deletion, the conditions were the same as above except that an annealing temperature of $60^{\circ} \mathrm{C}$ and a total number of 32 cycles was used. The amplified PCR products were visualized by UV-illumination on $2 \%$ agarose gel containing Gel Red (Biotium, Inc., Hayward, CA). The band reflecting the 4977 common deletion and all the other bands that were obtained at different levels on the gel were purified with Gel Extraction kits (Qiagen, Hilden, Germany), followed by commercial sequencing (GATC Biotech, Köln, Germany).

\section{Statistical analysis}

Differences in the rate of mtDNA deletions were analyzed using the Chi-square test. Statistical analyses were performed using SPSS for Windows computer package (IBM SPSS Statistics, 2012, version 19; SPSS Inc., Chicago, IL). Results were considered significant at $p<0.05$.

\section{Results}

Frequency of mtDNA 4977 bp deletion in patients with $B C$

All samples showed clear bands with mtDNA and 10398 primers representing $433 \mathrm{bp}$ and $246 \mathrm{bp}$ respectively (Figure 1). In lanes 2, 6 and 9 (Figure 1), three novel deletions were detected (700, 220 and $700 \mathrm{bp}$, respectively) which were confirmed by sequencing. For the $4977 \mathrm{bp}$ deletion, represented by bands $381 \mathrm{bp}$, we defined two types of signals by nested PCR: negative and positive clear band (Table 2). The deletion was detected in $68.8 \%$ $(73 / 106)$ of cancerous tissues and $84.0 \%(89 / 106)$ of normal paired tissues (Table 2) $(p<0.01)$.

With regard to disease stage, the patients were divided into two sub-groups, one with no metastasis to lymph node or other organs (T1-3, N0, M0) and one with spread (T1-4, N1-3, M0-1). However, no significant difference was seen with respect to the frequency of 4977 bp deletion. Nor were tumor grade or age associated with the $4977 \mathrm{bp}$ deletion (data not shown).

We found a significantly $(p<0.01)$ higher rate of the 4977 bp deletion in patients with ER+, 91.2\% (11/12) compared with ER-, 41.2\% (5/12). Neither PR nor HER2 showed statistically significant correlation to the presence of 4977 bp deletion.

Table 2 Mitochondrial DNA 4977-bp deletion in Vietnamese patients with breast cancer

\begin{tabular}{llll}
\hline & & \multicolumn{2}{l}{ Prevalence of deletion $(\mathbf{n})$} \\
\cline { 4 - 4 } Parameters & No. of cases & Negative & Positive \\
\hline Cancer tissue & 106 & 33 & 73 \\
Normal paired tissue & 106 & 17 & 89 \\
Stage* & & & \\
T1N0M0 & 8 & 2 & 6 \\
T2N0M0 & 42 & 12 & 30 \\
T3N0M0 & 5 & 2 & 3 \\
T1N1M0 & 2 & 1 & 1 \\
T1N2M0 & 2 & 2 & 0 \\
T2N1M0 & 28 & 6 & 22 \\
T2N2M0 & 3 & 2 & 1 \\
T3N1M0 & 7 & 2 & 5 \\
T3N2M0 & 1 & 0 & 1 \\
T4N1M0 & 6 & 3 & 3 \\
T2N1M1 & 2 & 1 & 1 \\
\hline
\end{tabular}

${ }^{*}$ Cancer tissue. 


\section{Detection of novel mtDNA deletions}

After nested PCR, we detected different bands in addition to the $381 \mathrm{bp}$ which represents the $4977 \mathrm{bp}$ deletion. The bands that were both larger and smaller than 381 bp were purified, sequenced and the corresponding deletions were analyzed using the program BLASTn (Altschul et al. 1990). The deletions were checked against the MITOMAP database (MITOMAP 2013) and other possible reference sources, with the consequence that we characterize our findings as novel deletions. Tables 3 and 4 summarize the novel deletions in tumor and normal tissue with information about breakpoints, deletion size, repeat location and type, respectively. We found 36 novel deletions in the tumor tissue distributed

Table 3 Novel mtDNA deletion $(n=36)$ detected in breast cancer tissue

\begin{tabular}{|c|c|c|c|c|}
\hline Patient code & Deletion junction (nt:nt) & Deletion size (bp) & Repeat location (nt) & Repeat type \\
\hline 8 & $8712: 13256$ & 4543 & 8709-8711/13256-13258 & $1,3 / 3$ \\
\hline 10 & $8318: 13500$ & 5181 & - & NR \\
\hline 11 & 8249:12960 & 4710 & - & NR \\
\hline 20 & $8228: 13479$ & 5250 & $8228 / 13478$ & $D, 1 / 1$ \\
\hline 26 & 8329:13411 & 5081 & 8330-8333/13409-13412 & $1,4 / 4$ \\
\hline 28 & 8300:13448 & 5147 & - & NR \\
\hline 30 & $8439: 13080$ & 4640 & 8435-8439/13074-13079 & $D, 5 / 6$ \\
\hline 31 & $8241: 13278$ & 5036 & $8241 / 13277$ & $D, 1 / 1$ \\
\hline 32 & $8405: 13165$ & 4759 & 8404-8405/13163-13164 & $D, 2 / 2$ \\
\hline 33 & 8553:13206 & 4652 & $8552-8553 / 13206-13207$ & $1,2 / 2$ \\
\hline 33 & $8338: 12588$ & 4249 & 8333-8338/12582-12587 & $D, 5 / 6$ \\
\hline 38 & $8271: 13358$ & 5086 & $8271 / 13357$ & $D, 1 / 1$ \\
\hline 39 & 8532:13397 & 4864 & 8526-8532/13390-13396 & $D, 7 / 7$ \\
\hline 41 & $8586: 13457$ & 4870 & $8582-8586 / 13452-13456$ & $D, 4 / 5$ \\
\hline 44 & $8282: 13488$ & 5205 & 8279-8282/13484-13487 & $D, 4 / 4$ \\
\hline 44 & 8309:13474 & 5164 & 8310-8315/13474-13479 & $D, 6 / 6$ \\
\hline 52 & $8256: 13412$ & 5155 & - & NR \\
\hline 53 & $8436: 13528$ & 5091 & $8430-8436 / 13520-13527$ & $D, 5 / 7$ \\
\hline 55 & $8223: 13415$ & 5191 & - & NR \\
\hline 56 & 8319:13498 & 5178 & 8320-8321/13498-13499 & $1,2 / 2$ \\
\hline 60 & 8272:12908 & 4635 & $8272 / 12907$ & $D, 1 / 1$ \\
\hline 61 & $8474: 13525$ & 5050 & 8463-8474/13514-13524 & $D, 10 / 12$ \\
\hline 68 & $8273: 13138$ & 4864 & - & NR \\
\hline 69 & $8227: 13422$ & 5194 & 8227-8228/13420-13421 & $1,2 / 2$ \\
\hline 70 & $8448: 13499$ & 5050 & - & NR \\
\hline 73 & $8216: 13473$ & 5256 & $8216 / 13472$ & $D, 1 / 1$ \\
\hline 76 & $8262: 13415$ & 5152 & $8260-8262 / 13412-13414$ & $D, 2 / 3$ \\
\hline 77 & $8354: 13411$ & 5056 & - & NR \\
\hline 79 & $8252: 13490$ & 5237 & - & NR \\
\hline 86 & $8324: 13491$ & 5166 & 8310-8324/13474-13490 & $D, 13 / 17$ \\
\hline 90 & $8282: 13488$ & 5205 & 8279-8282/13484-13487 & $D, 4 / 4$ \\
\hline 91 & 8296:13372 & 5076 & 8294-8296/13370-13372 & $D, 3 / 3$ \\
\hline 99 & $8222: 13440$ & 5217 & $8222 / 13439$ & $D, 1 / 1$ \\
\hline 101 & 8443:13496 & 5052 & 8441-8443/13492-13495 & $D, 3 / 4$ \\
\hline 102 & 8369:12552 & 4182 & $8370-8379 / 12551-12559$ & $1,9 / 10$ \\
\hline 102 & $8505: 13405$ & 4899 & $8503-8507 / 1340-1344$ & l, 5/5 \\
\hline
\end{tabular}

$\mathrm{D}$, direct repeat; $\mathrm{NR}$, no repeat; $\mathrm{nt}$, nucleotide; I, indirect repeat. 
Table 4 Novel mtDNA deletion $(n=30)$ detected in breast normal tissue

\begin{tabular}{|c|c|c|c|c|}
\hline Patient code & Deletion junction (nt:nt) & Deletion size (bp) & Repeat location (nt) & Repeat type \\
\hline 4 & $8251: 13414$ & 5162 & 8244-8250/13409-13415 & $D, 7 / 7$ \\
\hline 6 & $8257: 13447$ & 5189 & $8257 / 13446$ & $D, 1 / 1$ \\
\hline 8 & $8226: 13459$ & 5232 & 8225-8227/13459-13461 & $D, 3 / 3$ \\
\hline 9 & $8326: 13480$ & 5153 & 8327-8328/13479-13480 & $D, 2 / 2$ \\
\hline 11 & 8332:13210 & 4877 & - & NR \\
\hline 19 & 8313:13522 & 5208 & $8314-8316 / 13521-13523$ & $D, 3 / 3$ \\
\hline 19 & 8300:13206 & 4905 & 8299-8300/13204-13205 & $D, 2 / 2$ \\
\hline 20 & $8263: 13461$ & 5197 & $8259-8263 / 13457-13461$ & l, $5 / 5$ \\
\hline 20 & $8231: 13328$ & 5096 & 8228-8231/13328-13332 & $D, 4 / 5$ \\
\hline 24 & 8564:13334 & 4769 & 8560-8564/13328-13332 & $D, 5 / 5$ \\
\hline 28 & $8305: 13533$ & 5227 & 8304-8305/13531-13532 & $D, 2 / 2$ \\
\hline 32 & $8256: 13313$ & 5056 & 8254-8257/13309-13312 & l, $4 / 4$ \\
\hline 38 & $8435: 13474$ & 5038 & 8434-8435/13472-13473 & $D, 2 / 2$ \\
\hline 41 & 8396:13466 & 5069 & 8395-8396/13464-13465 & $D, 2 / 2$ \\
\hline 43 & 8299:13463 & 5163 & 8294-8299/13457-13462 & $D, 5 / 6$ \\
\hline 50 & $8234: 13286$ & 5051 & 8231-8234/13283-13285 & $D, 3 / 4$ \\
\hline 52 & $8297: 13428$ & 5130 & 8295-8297/13425-13427 & $D, 2 / 3$ \\
\hline 52 & $88801: 13462$ & 4660 & 8787-8801/13448-13461 & D, 13/15 \\
\hline 59 & $8355: 13440$ & 5084 & 8343-8355/13428-13439 & D, $11 / 13$ \\
\hline 61 & $8216: 13396$ & 5179 & - & NR \\
\hline 65 & 8425:13297 & 4871 & 8421-8425/13291-13296 & l, 5/6 \\
\hline 67 & $8362: 13465$ & 5102 & 8363-8364/13465-13466 & $1,2 / 2$ \\
\hline 79 & 8492:13529 & 5036 & $8491-8492 / 13527-13528$ & $D, 2 / 2$ \\
\hline 79 & $8215: 13117$ & 4901 & $8214-8215 / 13115-13116$ & $D, 2 / 2$ \\
\hline 88 & $9160: 12966$ & 3805 & 9149-9160/12954-12965 & D, $12 / 12$ \\
\hline 92 & $8556: 13170$ & 4613 & 8553-8556/13166-13169 & $D, 3 / 4$ \\
\hline 101 & 8349:13421 & 5071 & 8348-8349/13419-13420 & $D, 2 / 2$ \\
\hline 103 & $8312: 13467$ & 5154 & $8313 / 13466$ & $D, 1 / 1$ \\
\hline 106 & 8259:12994 & 4734 & - & NR \\
\hline 107 & 8534:13399 & 4864 & 8526-8534/13390-13398 & $D, 8 / 9$ \\
\hline
\end{tabular}

$\mathrm{D}$, direct repeat; NR, no repeat; nt, nucleotide; l, indirect repeat.

among 33 patients and 30 novel deletions in the normal tissue spread over 26 patients.

A number of patients with at least one novel deletion in the cancerous tissue were 12 with no involved lymph nodes (N0) and in 21 with involved lymph nodes (N1-2). Moreover, we observed, in cancerous tissue, a significantly $(p<0.05)$ higher rate, $41.2 \%(21 / 51)$, of the novel deletions in the group of patients defined as N1-2 in comparison with $21.8 \%(12 / 55)$, in the group defined as No. However, this result is not consistent with good statistical power which has a value around 0.6. There were no associations between the novel deletions and other clinical characteristics and no associations in the normal tissue (data not shown).

\section{Observed novel mtDNA single nucleotide variants}

Fifteen novel mtDNA single nucleotide variants were identified in the region sequenced and resident in the novel deletions reported here (Table 5). These were not linked to any clinical parameter available in this study (data not shown).

\section{Discussion}

The mitochondrial 4977 bp deletion has been found in tissues from several tumor types and adjacent normal tissues (Penta et al. 2001; Chen et al. 2011; Ye et al. 2008; Abnet et al. 2004; Dai et al. 2006). Recently, reduced mitochondrial mutagenesis in colorectal cancer has been shown, as well as a higher frequency of mtDNA 
Table 5 Novel mtDNA single nucleotide variants detected in breast cancer and normal tissue

\begin{tabular}{lll}
\hline Sample no. & Tissue & Variant \\
\hline 10 & Cancer & T13543A \\
19 & Normal & T13386A \\
20 & Normal & A13395G \\
24 & Normal & G13414A \\
43 & Normal & T13460C \\
52 & Normal & G8790C \\
59 & Normal & C8349T \\
61 & Cancer & C8472A, A13519C \\
68 & Cancer & A13395G \\
77 & Cancer & C8270T, C13503T \\
86 & Cancer & G13480T, T8317G \\
104 & Cancer & T13488C \\
\hline
\end{tabular}

mutagenesis, which may prevent colorectal cancer (Ericson et al. 2012). In the present study, the mtDNA 4977 bp deletion was found at a significantly higher frequency in normal tissue in comparison with paired cancer tissue in Vietnamese BC patients. We also observed a pervading heteroplasmy in the tissues. Our results are consistent with a previous study showing decreased proportions of the mtDNA 4977 bp deletion in various cancer types compared with adjacent normal tissue, such as breast (Ye et al. 2008), lung (Dai et al. 2006), gastric (Wu et al. 2005) and colorectal cancer (Dimberg et al. 2014). One explanation of this phenomenon might be a dilution of the mtDNA 4977 bp deletion in tumor tissue as a result of clonal expansion during cancer progression or that cells harbouring this deletion are eliminated by apoptosis (Wu et al. 2005). Moreover, the mtDNA 4977 bp deletion might confer a metabolic disadvantage to proliferating cells and thus is selected out in the highly proliferative tumor tissue (Wu et al. 2005).

Testing the tumor for hormonal receptors is a standard part of a $\mathrm{BC}$ diagnosis. In general $\mathrm{BC}$ with positive hormonal receptor status tends to be more aggressive and fast growing. Moreover, the receptor status predicts the treatment response and thus will influence the treatment regimen (Goldhirsch et al. 2009). In the present study, we found that the incidence of the 4977 bp deletion in $\mathrm{BC}$ tissue is significantly higher in the patients with ER positive as compared with ER negative patients. It has been reported that p53 plays a role in the maintenance of mtDNA integrity by controlling replication and repair through interaction with DNA pol gamma (Achanta et al. 2005). A study demonstrated that ER binds to p53 on the p53 target gene and represses p53 mediated transcriptional activation (Konduri et al. 2010) and may thus explain that $4977 \mathrm{bp}$ deletion seems to be more prevalent among ER positive patients.

In addition to the 4977 bp deletion, we discovered novel large scale deletions, 36 in cancerous and 30 in normal tissue. Moreover, 15 novel mtDNA single nucleotide variants were identified within the region sequenced and resident in the novel deletions reported here.

Interestingly, we observed, in cancerous tissue, a significantly higher incidence of the novel deletions in the group of patients with lymph node metastasis in comparison with the patients with no lymph node metastasis. However, this result is preliminary because of insufficient number of patients. It is possible that our novel deletions are involved in the mediation of tumor progression. However, our finding does not provide answers as to whether mtDNA alterations are contributing factors to carcinogenesis or whether they simply arise as part of secondary effects in cancer progression. Whether our detected novel deletions have an impact on cancer development or not requires further investigation. Studies have shown that a reduced mtDNA content is associated with higher histological grade in BC (Yadav \& Chandra 2013) while other studies failed to demonstrate any correlation with tumor grade or metastasis (Yadav \& Chandra 2013; Mambo et al. 2005). In the future, it would be of interest to investigate this type of correlation in our group with increased number of patients.

To our knowledge, this is the first time that mtDNA alteration in $\mathrm{BC}$ tissue and paired normal tissue has been analyzed in Vietnamese patients. We have focused on identification of the 4977 bp deletion but also on characterization of novel mutations. The results about the novel mutations must be confirmed by expanding the investigation. Studies using increased sample size are required to determine the clinicopathologic role of the sequence variation of mtDNA in BC. Our finding may provide complementary information in additional studies to define the importance of the mtDNA deletions found in prediction of clinical outcome including metastasis, recurrence and survival of patients with $\mathrm{BC}$.

\section{Competing interests}

The authors declare that they have no competing interests.

\section{Authors' contributions}

JD and TTH: Conceived the study, participated in its design and in the sequence alignment, analyzed data and also prepared the manuscript. LTTN and MS: Carried out the laboratory work and the molecular genetic studies. SL and AM: Organized the laboratory work revised and edited the manuscript. All authors read and approved the final manuscript.

\section{Acknowledgements}

This work was supported by grants from Futurum the Academy of Healthcare, County Council of Jönköping, Sweden, the Foundation of Clinical Cancer Research, Jönköping Sweden and the University College of Health Sciences, Jönköping Sweden. This work was also financially supported by KC.04.10/11-15 project of Ministry of Science and Technology, Vietnam. 


\section{Author details}

${ }^{1}$ Department of Natural Science and Biomedicine, University College of Health Sciences, Jönköping, Sweden. ${ }^{2}$ Key Laboratory of Enzyme and Protein Technology, Department of Biology, College of Science, Vietnam National University, Hanoi, Vietnam. ${ }^{3}$ Departments of Clinical Microbiology, Ryhov County Hospital, Jönköping, Sweden. ${ }^{4}$ Departments of Laboratory Services, Ryhov County Hospital, SE-551 85 Jönköping, Sweden.

Received: 3 December 2014 Accepted: 22 January 2015

Published online: 03 February 2015

\section{References}

Abnet CC, Huppi K, Carrera A, Armistead D, McKenney K, Hu N, Tang ZZ, Taylor PR, Dawsey SM (2004) Control region mutations and the common deletion are frequent in the mitochondrial DNA of the patients with esophageal squamous cell carcinoma. BMC Cancer 40:1-8

Achanta G, Sasaki R, Feng L, Carew JS, Lu W, Pelicano H, Keating MJ, Huang P (2005) Novel role of p53 in maintaining mitochondrial genetic stability through interaction with DNA Pol gamma. EMBO J 24:3482-3492

Altschul SF, Gish W, Miller W, Myers EW, Lipman DJ (1990) Basic local alignment search tool. J Mol Biol 215:403-410

Anh PT, Duc NB (2002) The situation with cancer control in Vietnam. Jpn J Clin Oncol 57:S92-S97

Banin Hirata BK, Oda JM, Losi Guembarovski R, Ariza CB, de Oliveira CE, Watanabe MA (2014) Molecular markers for breast cancer: prediction on tumor behavior. Dis Markers 2014:e513158

Birch-Machin MA (2006) The role of mitochondria in ageing and carcinogenesis. Clin Exp Dermatol 31:548-552

Chen T, He J, Shen L, Fang H, Nie H, Jin T, Wei X, Xin Y, Jiang Y, Li H, Chen G, Lu J, Bai $Y$ (2011) The mitochondrial DNA 4,977-bp deletion and its implication in copy number alteration in colorectal cancer. BMC Med Genet 12:1-9

Dai JG, Xiao YB, Min JX, Zhang GQ, Yao K, Zhou RJ (2006) Mitochondrial DNA 4977 bp deletion mutations in lung carcinoma. Indian J Cancer 43:20-25

Dani SU, Dani MA, Simpson AJ (2003) The common mitochondrial DNA deletion $\triangle m t D N A$ (4977): sheding new light to the concept of a tumor suppressor mutation. Med Hypotheses 61:60-63

Dimberg J, Hong TT, Skarstedt M, Löfgren S, Zar N, Matussek A (2014) Novel and differential accumulation of mitochondrial DNA deletions in Swedish and Vietnamese patients with colorectal cancer. Anticancer Res 34:147-152

Ericson NG, Kulawiec M, Vermulst M, Sheahan K, O'Sullivan J, Salk JJ, Bielas JH (2012) Decreased mitochondrial DNA mutagenesis in human colorectal cancer. PloS Genet 8:e1002689

Eshaghian A, Vleugels RA, Canter JA, McDonald MA, Stasko T, Sligh JE (2006) Mitochondrial DNA deletions serve as biomarkers of aging in the skin but are typically absent in nonmelanoma skin cancers. J Invest Dermatol 126:336-344

Goldhirsch A, Ingle JN, Gelber RD, Coates AS, Thurlimann B, Senn HJ (2009) Thresholds for therapies: highlights of the St Gallen international expert consensus on the primarytherapy of early breast cancer 2009. Ann Oncol 20:1319-1329

Jemal A, Bray F, Center MM, Ferlay J, Ward E, Forman D (2011) Global cancer statistics. CA Cancer J Clin 61:69-90

Konduri SD, Medisetty R, Liu W, Kaipparettu BA, Srivastava P, Brauch H, Fritz P, Swetzig WM, Gardner AE, Khan SA, Das GM (2010) Mechanisms of estrogen receptor antagonism toward p53 and its implications in breast cancer therapeutic response and stem cell regulation. Proc Natl Acad Sci USA 107:15081-15086

Larman TC, DePalma SR, Hadjipanayis AG, Cancer Genome Atlas Research Network, Protopopov A, Zhang J, Gabriel SB, Chin L, Seidman CE, Kucherlapati R, Seidman JG (2012) Spectrum of somatic mitochondrial mutations in five cancers. Proc Natl Acad Sci USA 109:14087-14097

Le GM, Gomez SL, Clarke C, Glaser SL, West DW (2002) Cancer incidence patterns among Vietnamese in the United States and Hanoi. Int J Cancer 102:412-417

Mambo E, Chatterjee A, Xing M, Tallini G, Haugen BR, Yeung S-C J, Sukumar S, Sidransky D (2005) Tumor-specific changes in mtDNA content in human cancer. Int J Cancer 116:920-924

McPherson K, Steel CM, Dixon JM (2000) ABC of breast diseases. Breast cancerEpidemiology, risk factors and genetics. BMJ 321:624-628

MITOMAP (2013). http://www.mitomap.org/MITOMAP (last accessed June 30, 2013)

Penta JS, Johmson FM, Wachsman JT, Copeland WC (2001) Mitochondrial DNA in human malignancy. Mutat Res 488:119-133
Polyak K (2007) Breast cancer: origins and evolution. J Clin Invest 117:3155-3163

Schwartz GF, Hughes KS, Lynch HT, Fabian CJ, Fentiman IS, Robson ME, Domchek SM, Hartmann LC, Holland R, Winchester DJ (2008) Proceedings of the international consensus conference on breast cancer risk, genetics \& risk management, April 2007. Cancer 113:2627-2637

Wu CW, Yin PH, Hung WY, Li AF, Li SH, Chi CW, Wei YH, Lee HC (2005) Mitochondrial DNA mutations and mitochondrial DNA depletion in gastric cancer. Genes Chromosomes Cancer 44:19-28

Yadav N, Chandra D (2013) Mitochondrial DNA mutations and breast tumorigenesis. Biochim Biophys Acta 1836:336-344

Ye C, Shu XO, Wen W, Pierce L, Courtney R, Gao YT, Zheng W, Cai Q (2008) Quantitative analysis of mitochondrial DNA 4977-bp deletion in sporadic breast cancer and benign diseases. Breast Cancer Res 108:427-434

\section{Submit your manuscript to a SpringerOpen ${ }^{\odot}$ journal and benefit from:}

- Convenient online submission

- Rigorous peer review

- Immediate publication on acceptance

- Open access: articles freely available online

- High visibility within the field

- Retaining the copyright to your article

Submit your next manuscript at $>$ springeropen.com 